\title{
Wind-resistant optimization design of large storage tanks in island-type petrochemical parks
}

\author{
Haoran $\mathrm{Hu}^{1}$, Jian $\mathrm{Guo}^{2, *}$, Bingyuan Hong ${ }^{2, *}$, Yan $\mathrm{Yan}^{2}, \mathrm{Xu} \mathrm{Yang}^{1}$, and Baikang Zhu \\ ${ }^{1}$ School of Ships and Maritime, Zhejiang Ocean University, Zhoushan, 316022, China \\ ${ }^{2}$ School of Petrochemical and Environment, Zhejiang Ocean University, Zhoushan, 316022, China
}

\begin{abstract}
Due to the thin-walled wind-sensitive structures of large crude oil storage tanks, it is necessary to consider the wind load failure of oil storage tanks in coastal areas under strong wind conditions during the design process. Based on the finite element analysis software ANSYS $\backslash$ Workbench, the static structure analysis and buckling analysis of the 100,000 cubic crude oil storage tanks are carried out. In order to solve the buckling failure phenomenon, a wind-resistant ring structure was optimal designed for the crude oil storage tank according to standards, so that the storage tank can withstand hurricanes and typhoons above level 12 with a wind speed of $137 \mathrm{~km} / \mathrm{h}$.
\end{abstract}

\section{Overview}

China's oil consumption ranks second in the world [1], and the four main oil reserve bases are currently being built in the coastal area relying on ports [2]. These bases use 100,000 cubic meters of oil storage tanks with thinwalled shell structures, whose diameter/thickness ratio is usually greater than 1,000 , and can even reach 2500 or more [3]. The large diameter-thickness ratio causes large crude oil storage tanks to be easily unstable and damaged under strong wind loads. Typhoons are frequent in coastal areas, and if an accident occurs, it will cause serious economic losses and environmental pollution [4]. The wind load on the cylindrical shell has always been a research hotspot in the field of wind engineering [5]. In this paper, the wind load distribution law of 100,000 cubic large storage tank is studied through numerical simulation, and the wind stability bearing capacity of the storage tank structure is analysed for optimal design of the wind resistance circle.

\section{ANSYS finite element analysis of crude oil storage tank}

Taking a 100,000 cubic meter crude oil storage tank as the analysis object, the 3D grid of crude oil storage tank model is shown in Figure 1 below.

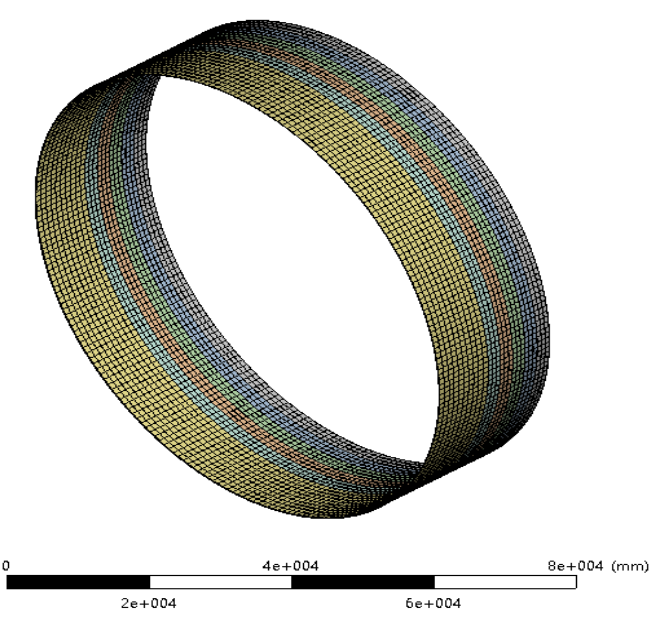

Fig. 1. The 3D grid of crude oil storage tank.

\subsection{Boundary condition}

The relationship between the wind load on the outer wall of the crude oil storage tank and the circumferential angle [6] is shown in Figure 2, which is loaded into the 3D model, as shown in Figures 3 and 4. 


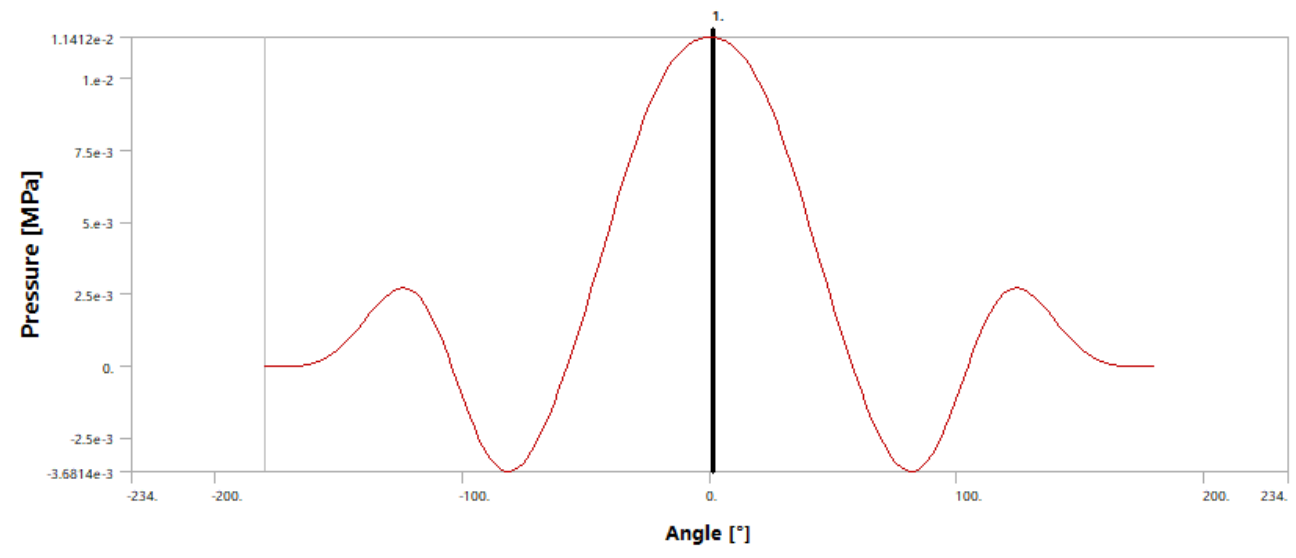

Fig. 2. Pressure load curve with circumferential angle.

A: satic sroctur
Pressure

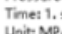

[0.014097324 Max
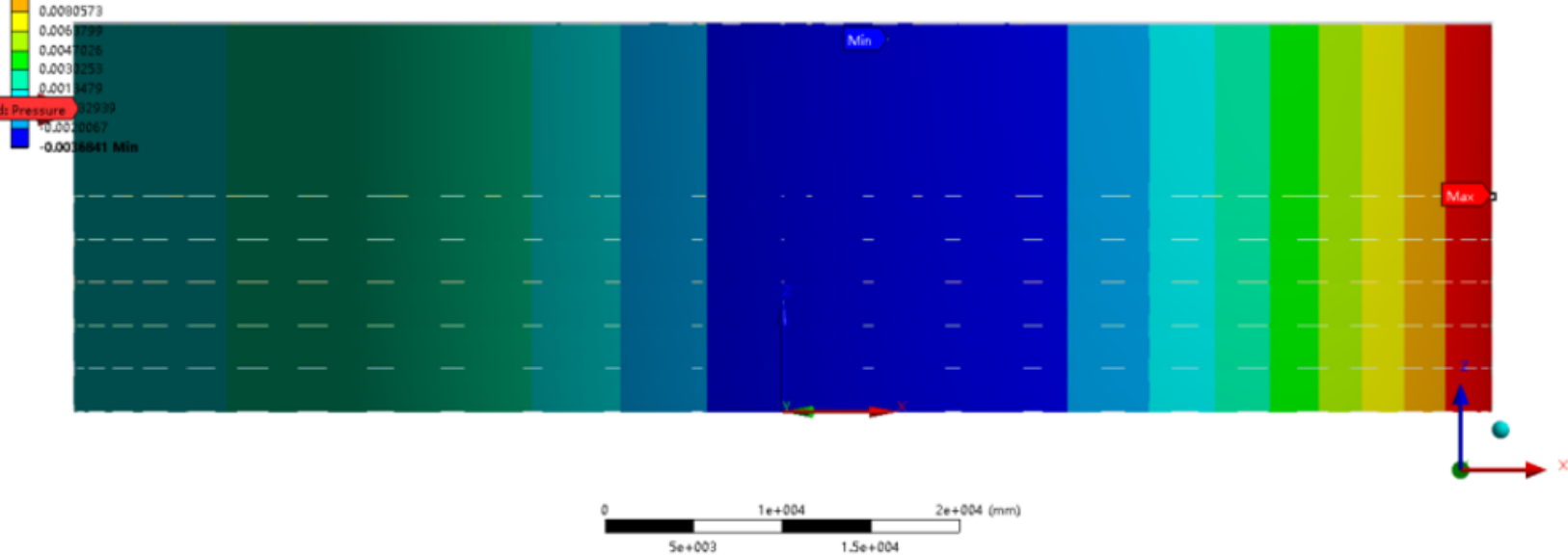

Fig. 3. $-180^{\circ}$ to $0^{\circ}$ load distribution.

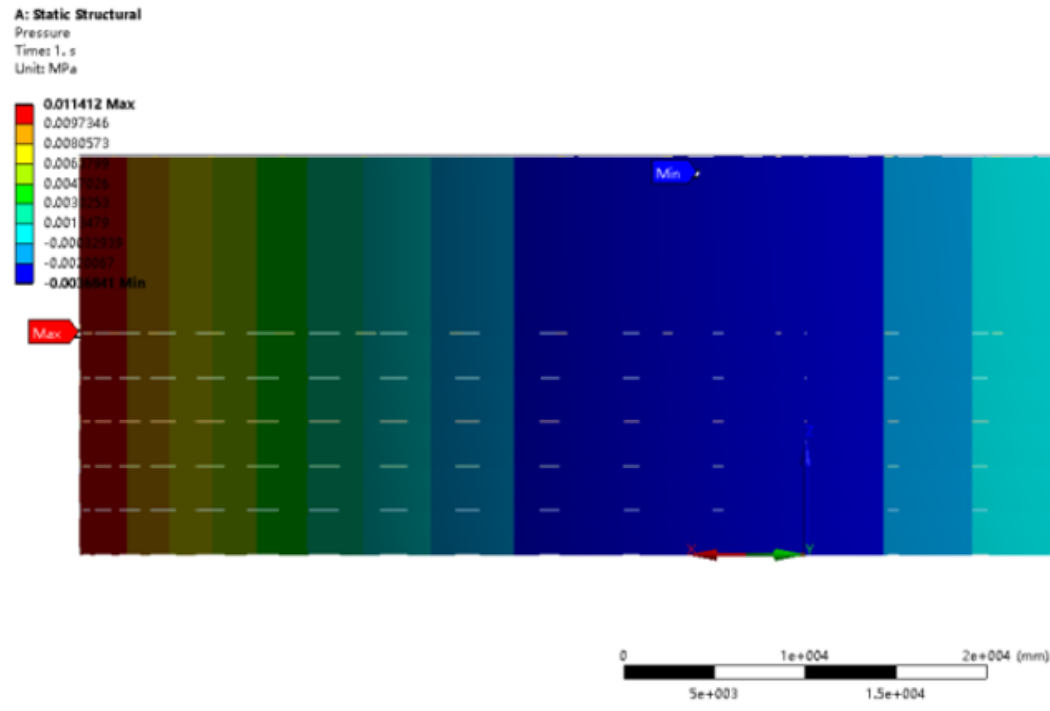

Fig. 4. $0^{\circ}$ to $180^{\circ}$ load distribution.

\subsection{Results analysis}

Figure 5 shows the buckling formation when there is no wind-resistant ring. A breeze at level 3 will cause buckling failure. Therefore, the crude oil storage tank must be designed with a wind-resistant ring. 


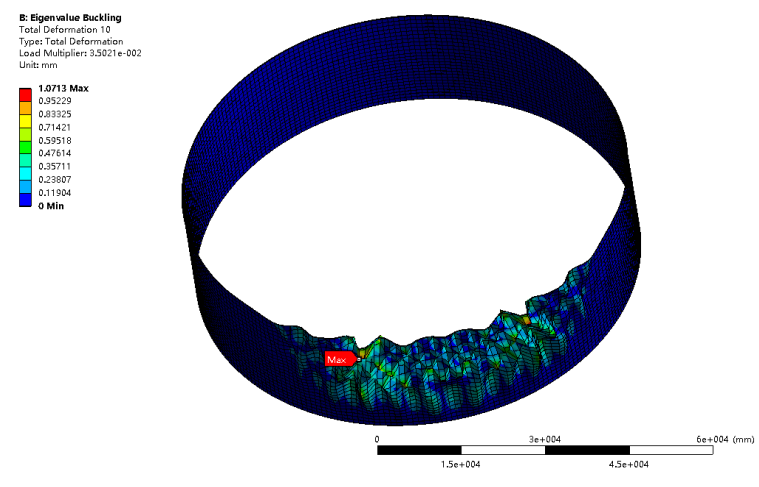

Fig. 5. Eigenvalue buckling without wind-resistant ring.

\section{Design of wind resistance ring}

\subsection{Wind-resistant ring design}

Coastal crude oil storage tanks are used in a harsher environment and have greater wind loads. The preliminary design adopts nine wind resistance rings. Considering the cost of processing and manufacturing, the structure of the wind-resistant ring should be as universal as possible [7,8]. Therefore, the nine windresistant rings have the same size and are evenly arranged on the outer wall of the storage tank. As shown in Figure 6, the blue circles stand for the wind-resistant rings.

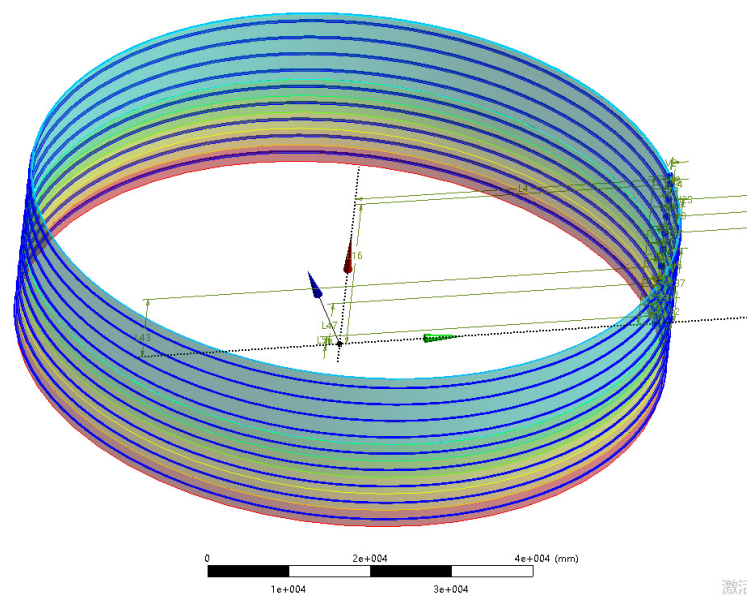

Fig. 6. Wind resistance scheme model diagram.

\subsection{Finite element stress and buckling checking}

According to the static structure analysis and buckling analysis of finite element, the surface deformation of the wind-resistant ring design scheme is obtained. The calculated results of characteristic values of buckling analysis are shown in Table 1 below.

Table 1. Buckling order characteristic values of crude oil storage tank with evenly arranged wind resistance.

\begin{tabular}{|c|c|}
\hline Order time & The eigenvalue \\
\hline 1 & 0.37556 \\
\hline 2 & 0.39299 \\
\hline 3 & 0.47098 \\
\hline
\end{tabular}

\begin{tabular}{|c|c|}
\hline 4 & 0.48043 \\
\hline 5 & 0.56669 \\
\hline 6 & 0.59374 \\
\hline 7 & 0.66921 \\
\hline 8 & 0.68639 \\
\hline 9 & 0.69768 \\
\hline 10 & 0.70038 \\
\hline 11 & 0.77445 \\
\hline 12 & 0.78836 \\
\hline
\end{tabular}

It can be seen from Table 1 that the 12-level eigenvalues are all less than 1 , so the preliminary design of the crude oil storage tank cannot withstand the 12level strong wind and will cause buckling failure. The first-order eigenvalue corresponds to the 9-class wind with a wind speed of $80 \mathrm{~km} / \mathrm{h}$, which meets the requirements of inland or general land use. However, there are still risks for coastal oil storage tanks focused on this paper, and further optimization is needed.

\section{Optimization of wind resistance ring}

\subsection{Analysis of preliminary design results}

According to the first six values of Table1, the buckling deformation mainly occurs at the position where the wind pressure on the windward side is the largest, and the buckling deformation mainly occurs above the middle of the tank, while the relative deformation below the middle part could be ignored. Therefore, in the optimal design, it can be considered increasing the distance between the bottom anti-wind rings and decreasing the distance between the top anti-wind rings, so as to transfer the excess performance of the bottom to the weak position at the top of the crude oil storage tank.

\subsection{Wind-resistant ring optimization design}

Through repeated adjustment and iterative analysis, the optimal wind-resistant ring location was finally decided, as shown in Table 2 below. A 3D model is established as shown in Figure 7 where the bold lines are the nine wind-resistant rings.

Table 2 Distance from each wind-resistant ring to the bottom of the tank.

\begin{tabular}{|c|c|}
\hline $\begin{array}{c}\text { Wind resistance } \\
\text { number }\end{array}$ & Distance to the bottom (mm) \\
\hline 1 & 1210 \\
\hline 2 & 4436 \\
\hline 3 & 7663 \\
\hline 4 & 10890 \\
\hline 5 & 12826 \\
\hline 6 & 14762 \\
\hline 7 & 16698 \\
\hline 8 & 18634 \\
\hline 9 & 20570 \\
\hline
\end{tabular}




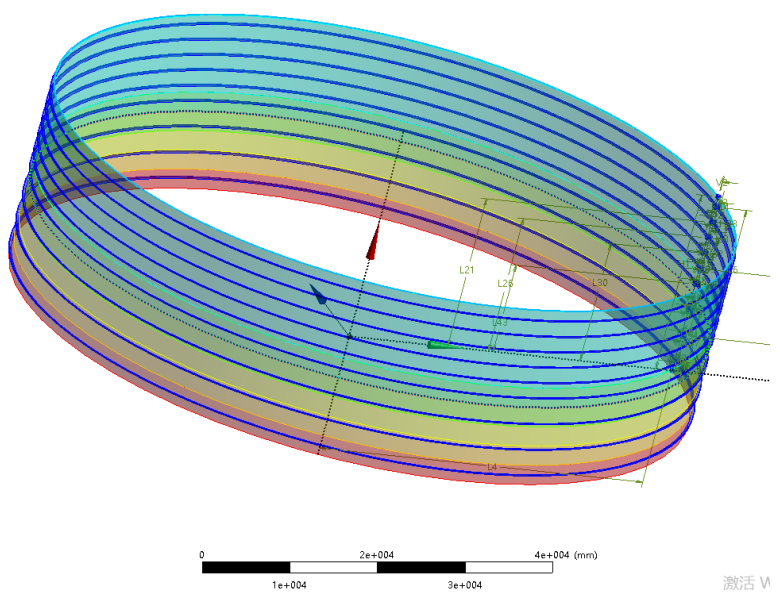

Fig. 7. Optimal location of wind-resistant ring.

According to the static analysis of finite element structure, the stress model of the optimal design scheme of wind resistance is obtained as shown in Figure 8 and 9. The main deformation of the crude oil storage tank is the inward depression in the direction of the wind surface. Among them, the position with the largest total deformation displacement is the top of the wind-exposed frontal tank, and its value is $14.013 \mathrm{~mm}$. Relative to its height, the deformation per unit length is $0.07 \%$, which is far less than the plastic deformation ratio of the metal material $2 \%$. Therefore, the deformation is within the normal range and will not cause failure.

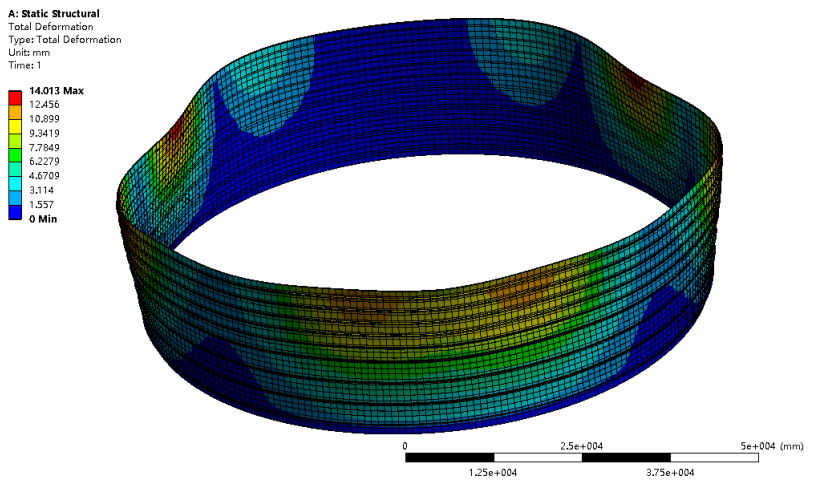

Fig. 8. Total deformation magnified 200 times.

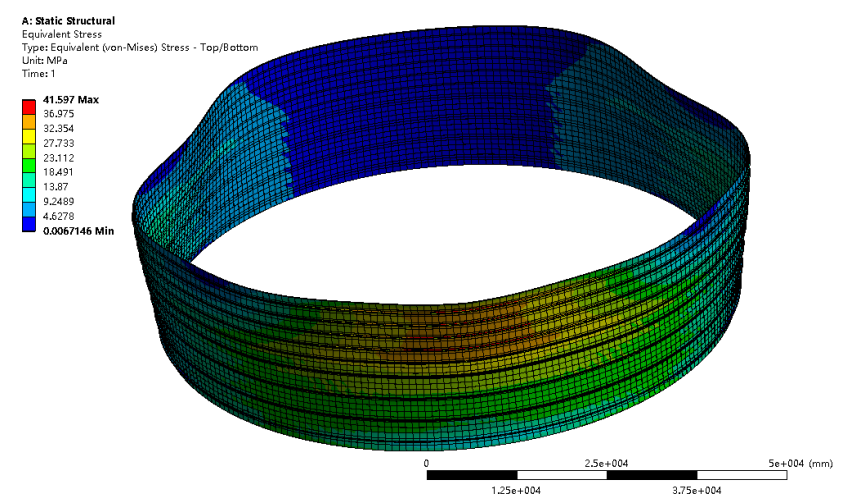

Fig. 9. Distribution of equivalent stress.

The characteristic values of buckling analysis are shown in Table 3. Figures $10 \sim 15$ are the buckling formation of wind-resistant. Those characteristic values are all greater than 1 , so the crude oil storage tanks with optimized wind resistance can withstand the high winds of class 12 and above. The first-order eigenvalue corresponds to the 12-class wind with a wind speed of $137 \mathrm{~km} / \mathrm{h}$, and can meet the requirements for the use of oil storage tanks in island-type petrochemical parks.

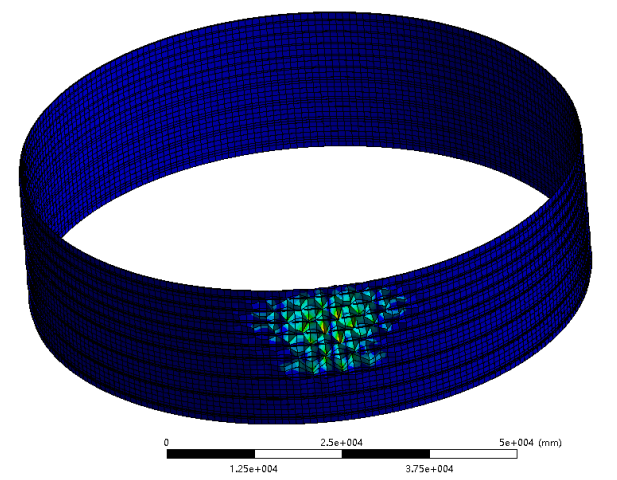

Fig. 10. First-order buckling formation of wind-resistant

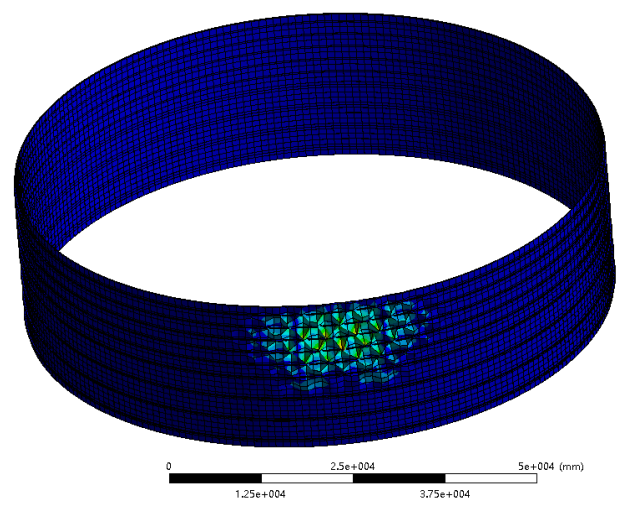

Fig. 11. Second-order buckling formation of wind-resistant

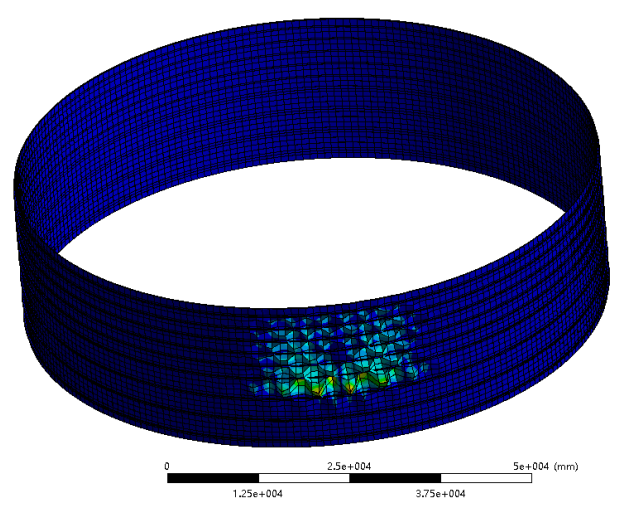

Fig. 12. Third-order buckling formation of wind-resistant 


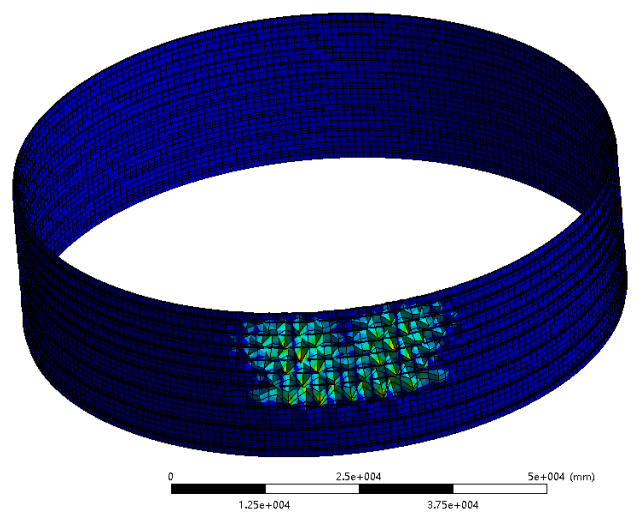

Fig. 13. Fourth-order buckling formation of wind-resistant

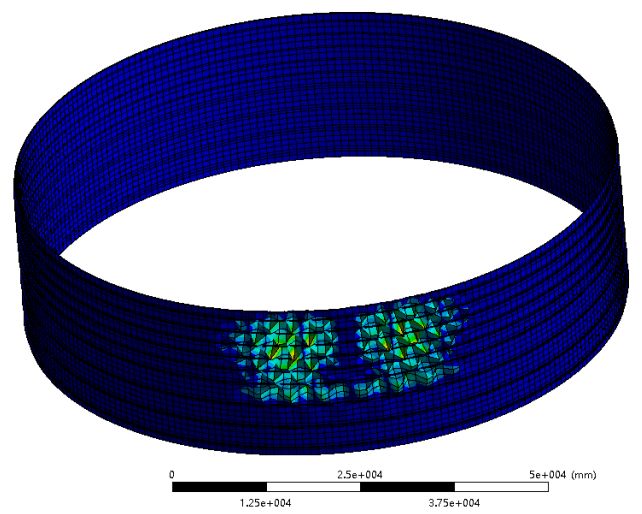

Fig. 14. Fifth-order buckling formation of wind-resistant

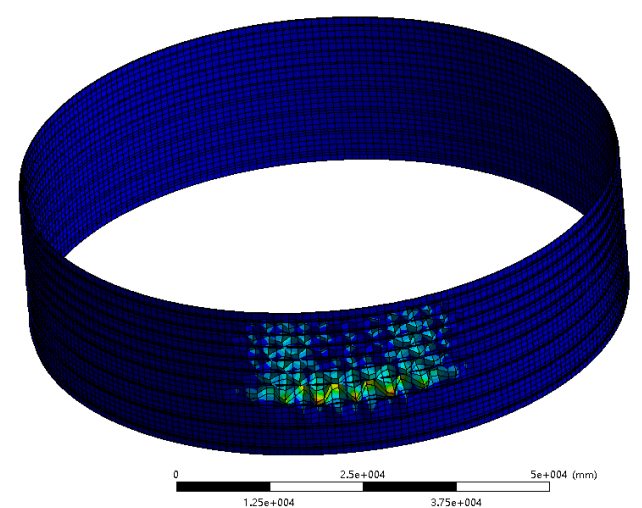

Fig. 15. Sixth-order buckling formation of wind-resistant

Table 3 Buckling order characteristic values of crude oil storage tank with optimized wind resistance.

\begin{tabular}{|c|c|}
\hline Order time & The eigenvalue \\
\hline 1 & 1.3191 \\
\hline 2 & 1.3368 \\
\hline 3 & 1.3651 \\
\hline 4 & 1.44 \\
\hline 5 & 1.473 \\
\hline 6 & 1.4995 \\
\hline 7 & 1.5578 \\
\hline 8 & 1.6107 \\
\hline 9 & 1.6764 \\
\hline 10 & 1.6869 \\
\hline 11 & 1.746 \\
\hline 12 & 1.8215 \\
\hline
\end{tabular}

\section{Conclusion}

In this paper, based on the finite element analysis software, the static structure analysis of the 100,000 cubic crude oil storage tank is carried out to find that the deformation and stress of the crude oil storage tank under wind load conditions are small and will not fail. After analyzing the storage tank structure and the failure phenomenon in the actual accidents, it is discovered that buckling may be the cause of wind load failure of large crude oil storage tanks. By buckling analysis, when there is no anti-wind ring, the level 3 breeze will cause buckling failure. In order to solve the buckling failure phenomenon, nine wind-resistant ring structures are designed that can withstand the 9-level wind speed of 80 $\mathrm{km} / \mathrm{h}$, which can reach inland or general land use requirements. Further iterative optimization of the height position of the anti-wind circle, and finally the storage tank can withstand hurricanes and typhoons above level 12 with wind speeds of $137 \mathrm{~km} / \mathrm{h}$.

\section{Acknowledgments}

Industrial Project of Public Technology Research of Zhejiang Province Science and Technology Department (LGG18E040001), and Scientific Research Project of Zhejiang Province Education Department (Y20173854).

\section{References}

1. T.Y. Li, C.K Tian, B. Cao, J.X. Zhang, H.Y Wu. Comprehensive study of energy situation in 2050 and strategy analysis of oil and gas enterprises Based on the comprehensive analysis of main energy outlook reports. International Petroleum Economics. J. 27, 11:1-9+33, (2019)

2. Z.J Yang, W. Li. Development situation and needs of China's petroleum reserve system. International Petroleum Economics. J. 23(09):69-77, (2015)

3. C. Zhang, J. Ma, Z. Zhang. A research of the strategic petroleum reserve in the new period. Military Economic Research. J. 26(12), (2015)

4. Z.C Zhang. Wind load and wind resistant stability of large steel tanks. Zhejiang University. D, (2017)

5. Yan. Lin. Wind load and wind-induced buckling of large steel tanks. Zhejiang University. D, (2014)

6. S.Y. Li. Research on Integrity Management of Large Crude Oil Storage Tanks. Xi'an Shiyou University. D, (2015)

7. J. Wei, J.X. Wang, X.S Cheng. Dynamic responses of oil storage tank considering wind interference effect. Engineering failure analysis. J. 104:10531063, (2019)

8. J. Yasunagaa, Y. Uematsub. Dynamic buckling of cylindrical storage tanks under fluctuating wind loading. Thin-Walled Structures. J. 150, 106677 , (2020) 